\title{
Exploring the combustion chemistry of a novel lignocellulose-derived biofuel: cyclopentanol. Part I: quantum chemistry calculation and kinetic modeling
}

\author{
Liming Cai ${ }^{\mathrm{a}, *}$, Leif Kröger ${ }^{\mathrm{b}}$, Malte Döntgen ${ }^{\mathrm{b}}$, Kai Leonhard ${ }^{\mathrm{b}}$, Krithika \\ Narayanaswamyc ${ }^{\mathrm{c}}$ S. Mani Sarathy ${ }^{\mathrm{d}}$, Karl Alexander Heufer ${ }^{\mathrm{e}}$, Heinz Pitsch ${ }^{\mathrm{a}}$ \\ ${ }^{a}$ Institute for Combustion Technology, RWTH Aachen University, 52056 Aachen, \\ Germany \\ ${ }^{b}$ Chair of Technical Thermodynamics, RWTH Aachen University, 52062 Aachen, \\ Germany \\ ${ }^{c}$ Department of Mechanical Engineering, Indian Institute of Technology Madras, Chennai \\ 600036, India \\ ${ }^{d}$ King Abdullah University of Science and Technology, Clean Combustion Research \\ Center, Thuwal 23955-6900, Saudi Arabia \\ ${ }^{e}$ Physico-Chemical Fundamentals of Combustion, RWTH Aachen University, 52056 \\ Aachen, Germany
}

\section{Abstract}

Biomass derived chemicals may offer sustainable alternatives to petroleum derived hydrocarbons, while also enhancing engine combustion performance with co-optimization of fuels and engines. This paper presents a numerical study on the oxidation and combustion of a novel biofuel compound, cyclopentanol. Its reaction kinetics and thermochemistry are first explored using ab initio quantum chemistry methods. Thermochemical properties are calculated for cyclopentanol and a set of its key oxidation intermediates. C-H bond dissociation energies of cyclopentanol are computed for different carbon sites. For the fuel radicals, the energy barriers of their ring-opening reactions

\footnotetext{
${ }^{*}$ Corresponding author:

Email address: lcai@itv.rwth-aachen.de (Liming Cai)
} 
and the potential energy surfaces of their oxidation reactions are determined. Based on the theoretical results, a chemical kinetic mechanism is proposed to describe the oxidation of cyclopentanol at low and high temperatures. The model is compared against data obtained from shock tube, rapid compression machine, combustion vessel, and counterflow burner experiments over a range of initial conditions. Furthermore, reaction pathway analysis is performed using the present mechanism to give insights into the underlying oxidation chemistry of cyclopentanol. It is found that the $\alpha$-radical of cyclopentanol undergoes preferably an alcohol-specific $\mathrm{HO}_{2}$ elimination reaction to form stable cyclopentanone and this reaction can strongly retard reactivity. The major reaction pathways of $\beta$ - and $\gamma$-radicals are similar to those of cyclopentyl radicals that are the sequential and formally direct reactions of fuel radicals with $\mathrm{O}_{2}$ to form cyclopentenols and $\mathrm{HO}_{2}$ radicals. The existence of the hydroxy moiety affects the bond dissociation energies and reaction barriers slightly favoring the chain-branching channel for $\gamma$-radicals at low temperatures.

Keywords:

Cyclopentanol, quantum chemistry calculation, reaction mechanism, reaction pathway analysis

\section{Introduction}

The growing need for environmental sustainability motivates the search for clean transportation fuels of the future. For spark-ignition engines, future fuel candidates need to provide better anti-knock performance, which corresponds to a low auto-ignition propensity. It has been found that the 
presence of the alcohol functional group and the cyclic structure can retard the ignition reactivity of hydrocarbon fuels $[1,2]$. Molecules with these two structural characteristics are thus of high interest for spark-ignition engine application.

From the standpoint of producing alternative fuels, Voll and Marquardt [3] proposed the reaction network flux analysis method to detect promising biofuel production routes. This method was extended later by Dahmen and Marquardt [4] and used to find optimal lignocellulosic biomass conversion pathways and corresponding biofuel products regarding process performance, such as the production yield or the energy of produced fuels, for a given network of competing conversion channels. One of the proposed biofuel compounds is cyclopentanol, which contains simultaneously a hydroxy moiety and a carbocyclic ring. Therefore, from a joint consideration of fuel conversion and consumption, cyclopentanol can be regarded as a promising fuel candidate for spark-ignition engine application.

While several studies have focused on the synthesis and production of cyclopentanol $[5,6]$, knowledge about its oxidation and combustion chemistry is missing in the literature. The primary goal of this work is to first explore the fundamental combustion chemistry of cyclopentanol in terms of theoretical calculation, chemical kinetic modeling, and experimental measurement. In this part, quantum chemistry calculations are performed to determine the thermochemical data of cyclopentanol and its reaction intermediates. Site-specific C-H bond dissociation energies (BDEs) of cyclopentanol are estimated. To understand the oxidation kinetics of cyclopentanol at low and high temperatures, the potential energy surfaces (PES) of oxidation reac- 
tions and the energy barriers of ring-opening reactions of fuel radicals are calculated, respectively. Based on the theoretical results, a chemical kinetic model is proposed for the oxidation of cyclopentanol. The model is validated against the experimental measurements presented in the second part of this paper, and is employed further to elucidate the detailed reaction pathways of cyclopentanol oxidation.

The presentation of this paper is organized as follows: The computational details and results of theoretical calculations are presented in Section 2, followed by the details about the model development described in Section 3. A brief model validation is given in Section 4. In Section 5, the detailed oxidation pathways of cyclopentanol are illustrated and discussed. The major findings of the present study are summarized in Section 6 .

\section{Theoretical calculations}

Quantum chemistry calculations have been performed to explore the oxidation chemistry of cyclopentanol. Simulations were performed with the Gaussian software package [7]. The computational details and results are described and discussed in the following.

\subsection{Thermochemistry}

Thermochemical properties were estimated for cyclopentanol $(\mathrm{RH})$ and 46 intermediate species produced during its oxidation. The intermediates include three fuel radicals ( $R$ ), three cyclopentenols, three peroxy radicals $\left(\mathrm{RO}_{2}\right)$, three hydroperoxides $(\mathrm{ROOH})$, ten hydroperoxy radicals $(\mathrm{QOOH})$, ten peroxy hydroperoxy radicals $\left(\mathrm{O}_{2} \mathrm{QOOH}\right)$, eight carbonylhydroperoxides (i. e., ketohydroperoxides (KET)), three alkoxy radicals (RO), cyclopentanone, 
and two cyclopentanoyl radicals. Conformers of radicals are generated based on their parent molecules. The structure geometry optimization starts with one equatorial and one axial cyclopentanol conformers with the alcohol group on the same or the opposite sides of the ring deflection, respectively.

Molecular geometries and harmonic frequencies are obtained at the B3LYP/TZVP level of theory and single-point energies are calculated at the B2PLYPD3/augcc-pVTZ level of theory. The computation employs an ultrafine grid and tight convergence settings. The estimated harmonic frequencies are not further scaled with empirical anharmonic factors [8]. Molecular structures are geometry-optimized following the Multi-Structure Reference-Structure (MSRS) approach proposed by Zheng et al. [9]. The two ring puckering modes of the five-membered carbon rings are approximated as transition from harmonic to free motion for the ring twisting mode and as harmonic oscillation for the ring enveloping mode, as described by Kilpatrick et al. [10]. The moments of inertia of the free rotations are calculated using the reduced mass of the harmonic ring twisting modes and the equilibrium puckering amplitude reported for cyclopentane ( $q_{0}=0.236 \AA$ ) [10]. The partition functions of anharmonic torsional motions and ring twisting $\left(\mathrm{Q}_{\mathrm{anh}}\right)$ are approximated using the model for transition from harmonic (HO) to free motion (FR) proposed by Chuang and Truhlar [11], $Q_{\text {anh }}=Q_{\mathrm{HO}} \cdot \tanh \left(\mathrm{Q}_{\mathrm{FR}} / \mathrm{Q}_{\text {class }}\right)$, in which $\mathrm{Q}_{\text {class }}$ is the classical harmonic oscillator partition function. It is found in this work that the ring twisting is ill-described at low-temperature when using the pure free rotor model.

The standard enthalpies of formation $\Delta h_{\mathrm{f}}(298.15 \mathrm{~K})$, standard entropies $s^{0}(298.15 \mathrm{~K})$, and specific heats $\left(c_{p}\right)$ are determined for the species men- 
tioned above. For each species, these thermochemical values are expressed in the form of standard NASA polynomial approximation [12]. The coefficients in the NASA polynomials are fitted to reproduce the calculated properties considering two temperature ranges of $100-1000 \mathrm{~K}$ and $1000-3000 \mathrm{~K}$. The NASA polynomials are available in the Supplementary Material as part of the proposed chemical model. The calculated specific heats of cyclopentanol are compared to those reported by Kabo et al. [13] in Fig. 1. Good agreement is observed. Note that, in the present study, the standard enthalpy of formation of cyclopentanol is taken from Wiberg et al. [14] and the values of the remaining species are calculated relative to cyclopentanol, using $\mathrm{H}_{2}$ and $\mathrm{O}_{2}$ for filling the missing elements relative to cyclopentanol.

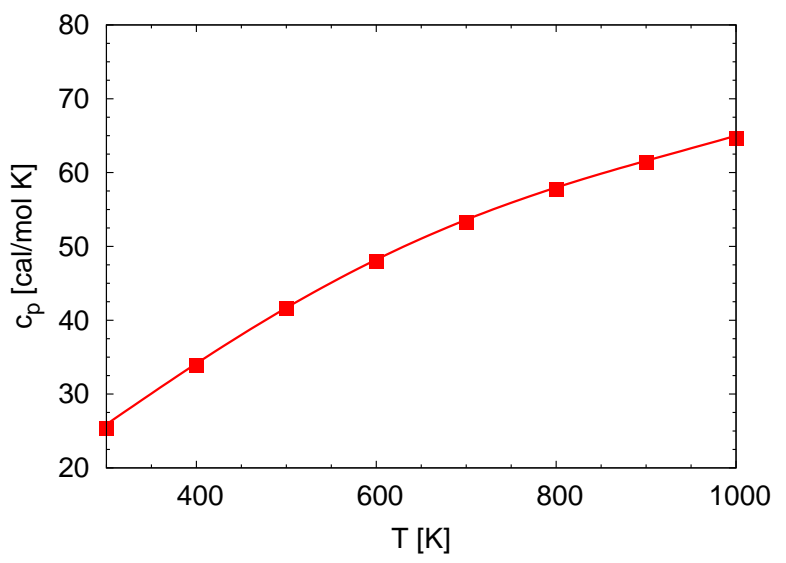

Figure 1: Specific heats of cyclopentanol. Symbols denote data from [13] and the line shows the calculated results.

\section{2. $C-H$ bond dissociation energy}

The breaking of a carbon-hydrogen bond is involved in various important reaction steps during the fuel oxidation, such as the H-abstraction of fuel, the 
fuel radical decomposition and isomerization, and the isomerization of peroxy and peroxy hydroperoxy radicals via intramolecular H-transfer. A weak C$\mathrm{H}$ bond can favor the $\mathrm{H}$-abstraction taking place at the respective carbon site and suppresses its competing reactions, thus affecting the fuel reactivity. Therefore, an accurate estimation of $\mathrm{C}-\mathrm{H}$ bond dissociation energies is a useful tool to estimate rate parameters for various reaction classes, especially for the oxidation of alcohols $[15,16]$.

The calculated BDEs are shown in Fig. 2 with the structure of cyclopentanol. To illustrate the naming of the species in the chemical model, cyclopentanol is denoted as $\mathrm{CPOH}$. Following the notation in the literature [17], the carbon sites are defined as $\alpha, \beta$, and $\gamma$ with regards to their positions relative to the hydroxy group and are labeled numerically in the chemical mechanism (i. e., 1, 2, 3). For example, the cyclopentanol radical at the $\alpha$-site, 1-hydroxycyclopentyl radical, is denoted by CPOHR1.

The BDEs are estimated at the CBS-QB3 level of theory. In comparison to cyclopentanol, the C-H BDE of cyclopentane is also determined and shown in Fig. 2. Cyclopentane is a symmetric molecule and each of the carbon sites possesses a C-H BDE of $97.1 \mathrm{kcal} / \mathrm{mol}$. With the substitution of a hydrogen atom by the hydroxy group in the molecule structure, the BDEs associated with the neighboring carbon sites are changed depending on their locations relative to the hydroxy group. It is seen in Fig. 2 that the presence of the $\mathrm{OH}$ moiety has a strong influence on the strength of the $\mathrm{C}-\mathrm{H}$ bonds connected to the $\alpha$-carbon atom. The $\mathrm{C}-\mathrm{H}$ BDE is decreased by $4 \mathrm{kcal} / \mathrm{mol}$ compared to that of cyclopentane. Note that the weakened $\mathrm{C}-\mathrm{H}$ bonding is not only attributed to the presence of the $\mathrm{OH}$ group, but is also a result 
of the rearrangement of the carbon nature. By substituting the hydrogen atom with the hydroxy group, the $\alpha$-carbon site varies from a secondary to a tertiary carbon. Normally, the tertiary carbon has the lowest bond energy and the connected hydrogen atoms are abstracted most easily. For example, as reported by Sarathy et al. [17], the C-H BDE of 2-butanol at the tertiary $\alpha$-carbon site is lower than that of 1-butanol at the secondary $\alpha$-carbon site. For the $\beta$-carbon site, the existence of the hydroxy moiety increases its $\mathrm{C}-\mathrm{H}$ BDE slightly by $0.5 \mathrm{kcal} / \mathrm{mol}$. The BDE at the $\gamma$-site is decreased by 0.5 $\mathrm{kcal} / \mathrm{mol}$. All of these findings are in agreement with the literature knowledge about the impact of the alcohol functional group on BDEs [17-19]. Overall, one would expect that reactions via $\mathrm{H}$-abstraction from the $\alpha$-carbon site become favorable in the oxidation of cyclopentanol.

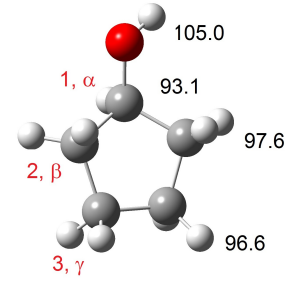

(a) Cyclopentanol

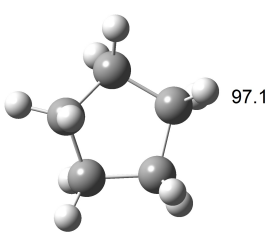

(b) Cyclopentane

Figure 2: Structures of cyclopentanol and cyclopentane and their C-H BDEs [kcal/mol] given at $298.15 \mathrm{~K}$. Gray, white, and red atoms indicate carbon, hydrogen, and oxygen, respectively.

\subsection{Potential energy surface of fuel radicals $+\mathrm{O}_{2}$}

The calculated $\mathrm{C}-\mathrm{H}$ bond dissociation energies provide an initial insight into the reaction kinetics of cyclopentanol. For a deeper understanding, especially of its oxidation pathways at low temperatures, the potential energy 
surfaces of the addition of molecular oxygen to cyclopentanol radicals are calculated. Single-point energies are calculated at the B2PLYPD3/aug-ccpVTZ level of theory, using geometries, frequencies, and zero-point energy corrections obtained at the B3LYP/TZVP level of theory. Stationary points are optimized using an ultrafine grid and tight convergence settings. Various conformations are examined for each stationary point to identify the global energetic minimum. The oxidation of cyclopentanol produces three hydroxycyclopentyl radicals. For each of these three fuel radicals, a PES is reported and the results are shown in Figs. 3-5.

A set of reactions are illustrated on the surfaces. The barrierless $\mathrm{O}_{2}$ addition to hydroxycyclopentyl radicals forms energized hydroxycyclopentyl peroxy radicals, which can either isomerize to QOOH species via internal Habstraction or eliminate $\mathrm{HO}_{2}$ to form cyclopentenols (e.g. CPOH1ENE). The $\beta$-scission reactions of QOOH species (e.g. $\mathrm{CPOH} 1 \mathrm{OOH} 2$ ) yielding cyclopentenols and $\mathrm{HO}_{2}$ are also included. For the 1-hydroxycyclopentyl radical, an alcohol-specific reaction channel is taken into account additionally, which proceeds via a weakly bound pre-reactive complex to produce cyclopentanone (CY-C5H8O) and $\mathrm{HO}_{2}$, following the suggestions of da Silva et al. [20] and Zádor et al. [21]. In this work, the barrier height of a reaction is defined as the energtic difference between its transition state and reactants and can be determined from the PESs.

Figure 3 shows the oxidation kinetics of the $\alpha$-fuel radical, i. e., the 1hydroxycyclopentyl (CPOHR1) radical. The well-depth of 1-hydroxycyclopentyl peroxy radical (CPOHR1OO) is $33.6 \mathrm{kcal} / \mathrm{mol}$. Its intramolecular H-migration via a six-membered transition state leading to 1-hydroxy-1-hydroperoxy-3- 
cyclopentyl radical (CPOH1OOH3) needs to overcome an energy barrier of $28.7 \mathrm{kcal} / \mathrm{mol}$. This isomerization channel is energetically favorable compared to that involving a five-membered transition state with a barrier of $33.5 \mathrm{kcal} / \mathrm{mol}$ and leading to 1-hydroxy-1-hydroperoxy-2-cyclopentyl radical (CPOH1OOH2). The isomerization of the peroxy radicals is an essential step in the low temperature chain-branching chemistry and promotes the fuel reactivity. For cyclopentanol, its peroxy radicals can isomerize only via fiveand six-membered transition state rings due to the molecular conformation. Also, it is worth mentioning that, as the isomerization takes place via highly strained bicyclic transition states, the estimated barriers are higher than those of the analogous reactions of linear compounds [22-24]. The concerted elimination of $\mathrm{HO}_{2}$ from peroxy radicals has been identified as an important side chain reaction in the oxidation of alkanes and oxygenated fuels [1, 17]. As described by Zádor et al. [25], the peroxy group leaves the molecule and simultaneously attracts an $\mathrm{H}$-atom from the adjacent carbon atom via a fivemembered transition ring. This reaction competes with the isomerization of peroxy radicals and thus inhibits the chain-branching pathway. Here, an energy barrier of $23.7 \mathrm{kcal} / \mathrm{mol}$ is estimated for the formation of 1-cyclopentenol and $\mathrm{HO}_{2}$ from the concerted elimination of the 1-hydroxycyclopentyl peroxy radical. The same products can also be obtained from the $\beta$-scission of $\mathrm{CPOH} 1 \mathrm{OOH} 2$ with a barrier of $16.7 \mathrm{kcal} / \mathrm{mol}$. Recently, da Silva et al. [20] and Zádor et al. [21] found in the oxidation of normal alcohols that the 1hydroxyalkyl radical can react with molecular oxygen to produce a weakly bound aldehyde $\cdots \mathrm{HO}_{2}$ complex with a very low energy barrier. This complex dissociates further to aldehyde and $\mathrm{HO}_{2}$ radical directly. In this work, 
a barrier height of $6.5 \mathrm{kcal} / \mathrm{mol}$ is determined for the analogous reaction of the 1-hydroxycyclopentyl radical, which yields cyclopentanone and $\mathrm{HO}_{2}$. As the barrier of this reaction is much lower than those of the isomerization and $\mathrm{HO}_{2}$ elimination reactions, it is expected to be the major consumption channel of the 1-hydroxycyclopentyl radical at low temperatures. This reaction initializes a chain-propagation, inhibits the chain-branching, and thus decreases the fuel reactivity.

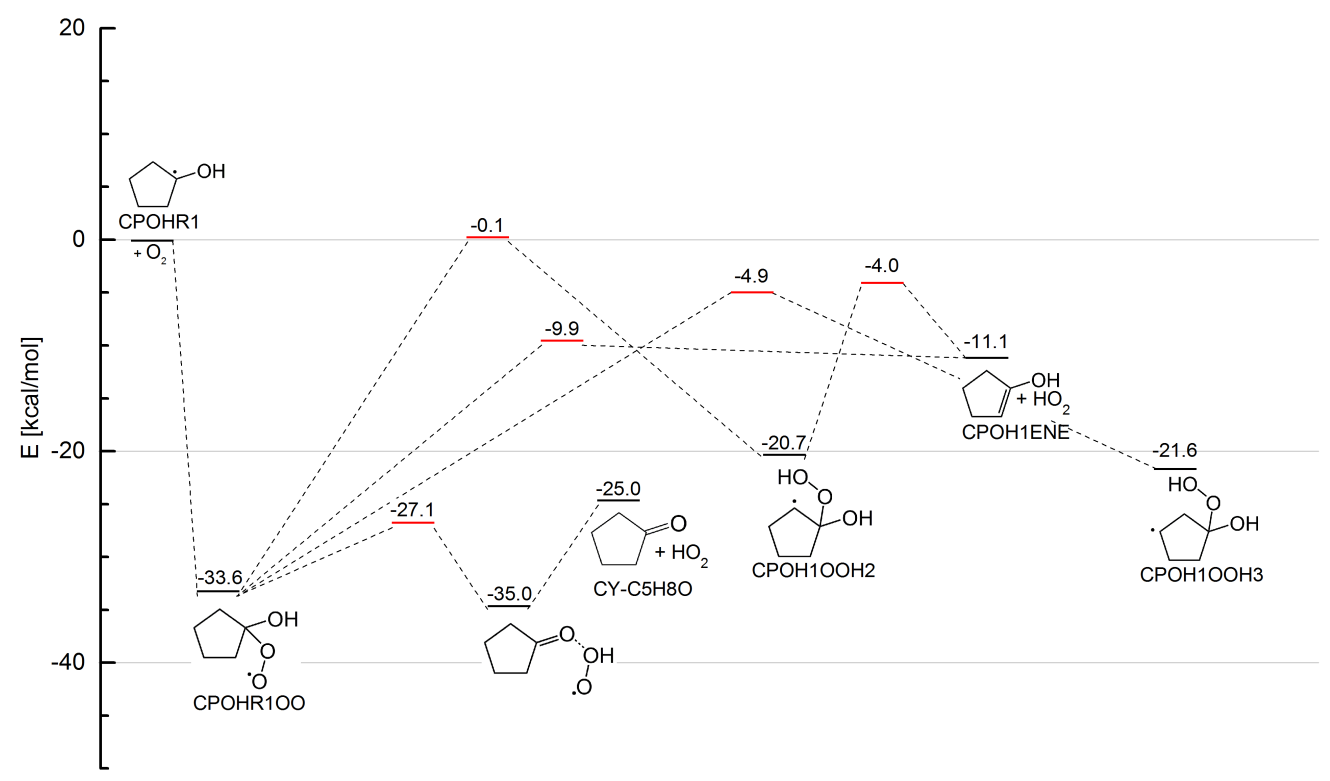

Figure 3: Potential energy surface for 1-hydroxycyclopentyl radical $+\mathrm{O}_{2}$.

Figure 4 depicts the fate of the 2-hydroxycyclopentyl radical (CPOHR2). It is shown that its peroxy radical (CPOHR2OO) can isomerize via four channels to form hydroperoxy radicals. The highest-energy reaction (33.4 $\mathrm{kcal} / \mathrm{mol}$ ) involves a transition state with a five-membered ring and an intramolecular $\mathrm{H}$-atom shift from the $\beta$-carbon site, giving the 1-hydroxy-2hydroperoxy-3-cyclopentyl radical (CPOH2OOH3). Based on six-membered 
transition states, CPOHR2OO can isomerize to 1-hydroxy-2-hydroperoxy-4cyclopentyl (CPOH2OOH4) and 1-hydroxy-2-hydroperoxy-5-cyclopentyl (CPOH2OOH5) radicals over barriers of 26.6 and $26.0 \mathrm{kcal} / \mathrm{mol}$, respectively. These results agree with the general understanding on the isomerization of peroxy radicals $[26,27]$. Five-membered isomerization has normally higher energy barrier compared with a six-membered transition state ring. Note that a low energy barrier of $25.6 \mathrm{kcal} / \mathrm{mol}$ is estimated here for the formation of the 1-hydroxy-2-hydroperoxy-1-cyclopentyl radical (CPOH2OOH1) via a fivemembered isomerization. As this reaction transfers a hydrogen atom from the $\alpha$-carbon site, its low barrier can be attributed to the weak $\mathrm{C}-\mathrm{H}$ bond at this $\alpha$-site. It is illustrated in Fig. 4 that the 1-hydroxy-2-hydroperoxy-1cyclopentyl and 1-hydroxy-2-hydroperoxy-3-cyclopentyl radicals can dissociate to cyclopentenols and $\mathrm{HO}_{2}$ with barriers of 11 and $13.9 \mathrm{kcal} / \mathrm{mol}$, respectively. The direct $\mathrm{HO}_{2}$ elimination from CPOHR2OO gives 1-cyclopentenol (CPOH1ENE) with an energy barrier of $24.1 \mathrm{kcal} / \mathrm{mol}$ and is the most energetically favored channel for CPOHR2OO on this surface. Similar barrier height is required for the $\mathrm{HO}_{2}$ elimination of the 1-hydroxycyclopentyl radical. It was found by Villano et al. [22] that the rate constants of the concerted $\mathrm{HO}_{2}$ elimination of peroxy radicals are independent of the nature of the broken $\mathrm{C}-\mathrm{H}$ and C-OO bonds. Moreover, as demonstrated here and in literature studies [28, 29], this reaction class is of growing importance in the oxidation of cyclic species, where the energy barriers of isomerization reactions are increased due to their bicyclic transition states

The PES of 3-hydroxycyclopentyl radical (CPOHR3) $+\mathrm{O}_{2}$ reactions is shown in Fig. 5. The well-depth of the 3-hydroxycyclopentyl peroxy radical 


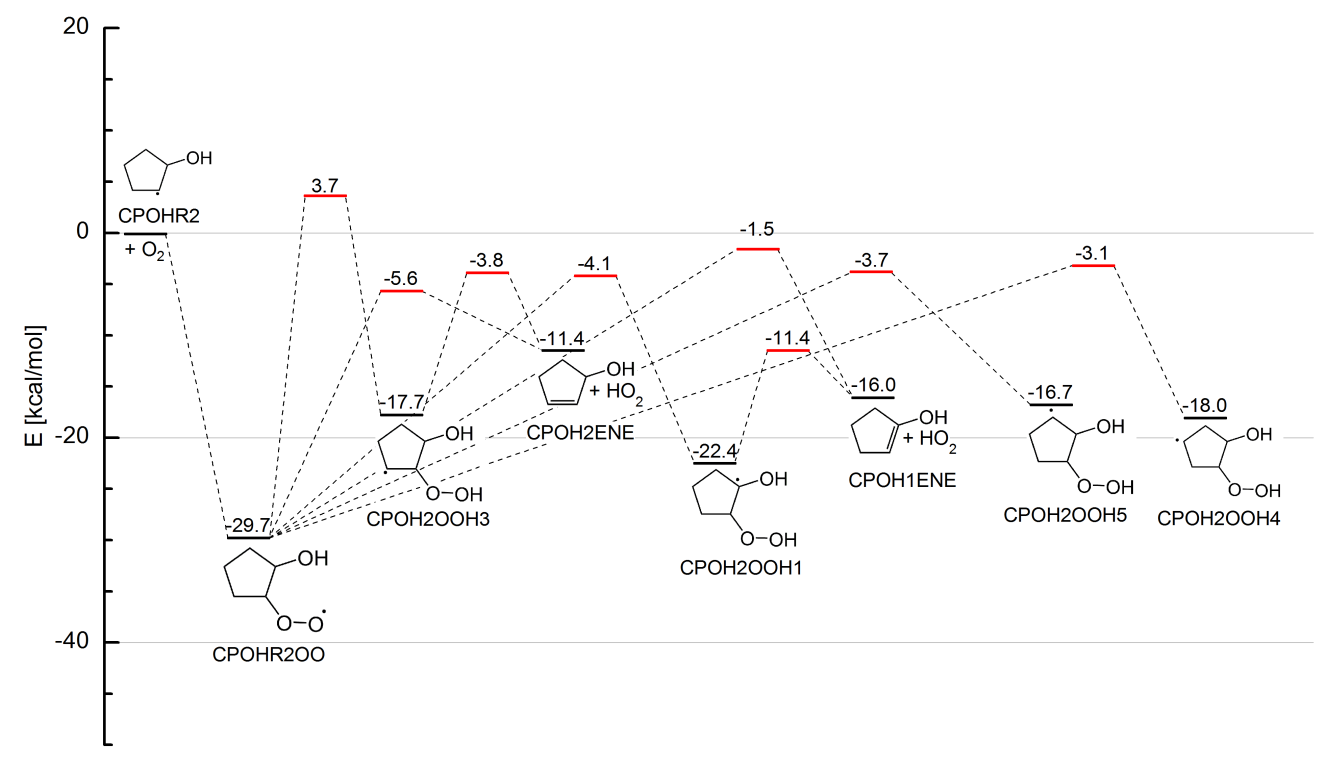

Figure 4: Potential energy surface for 2-hydroxycyclopentyl radical $+\mathrm{O}_{2}$.

(CPOHR3OO) is $30.1 \mathrm{kcal} / \mathrm{mol}$, which is comparable to that of CPOHR2OO. Six reaction channels are available for the CPOHR3OO radical. The isomerization of CPOHR3OO to the 1-hydroxy-3-hydroperoxy-1-cyclopentyl radical (CPOH3OOH1) occurs via a six-membered transition state ring and shifts an $\mathrm{H}$-atom from the weak $\alpha$-carbon site to the peroxy moiety. This reaction provides the lowest energy route $(24.6 \mathrm{kcal} / \mathrm{mol})$ for the 3 -hydroxycyclopentyl peroxy radical on this surface. The second 6-membered isomerization channel requires a higher energy barrier of $27.5 \mathrm{kcal} / \mathrm{mol}$, as the $\mathrm{H}$ atom is abstracted from the $\gamma$-carbon site with stronger $\mathrm{C}-\mathrm{H}$ bonds. Larger energy barriers of more than $30 \mathrm{kcal} / \mathrm{mol}$ are required to facilitate the five-membered isomerization reactions of CPOHR3OO radicals. On this PES, the formation of the 1-hydroxy-3-hydroperoxy-2-cyclopentyl (CPOH3OOH2) radical is identified as the path with the highest barrier $(36.7 \mathrm{kcal} / \mathrm{mol})$. The con- 
certed elimination of CPOHR3OO radicals forms 2- and 3-cyclopentenols with barriers of $\sim 25 \mathrm{kcal} / \mathrm{mol}$. It can be observed that the PESs of 2and 3-hydroxycyclopentyl radicals $+\mathrm{O}_{2}$ are similar. For peroxy radicals, both direct $\mathrm{HO}_{2}$ elimination and six-membered isomerization are expected to be important. For the 2-hydroxycyclopentyl peroxy radical, the concerted elimination is the most energetically favorable channel. For the 3hydroxycyclopentyl peroxy radical, the low BDE at the $\alpha$-carbon site promotes the intramolecular hydrogen shift from this site to the peroxy group via a six-membered transition ring, which is the lowest energy route on the respective PES. It is worth mentioning that, in this work, rate constants are not determined for the reactions on the PESs. It is difficult to quantify accurately the impact of the hydrocarbon ring on the entropy of transition states. The estimation of rate constants may thus involve large uncertainties.

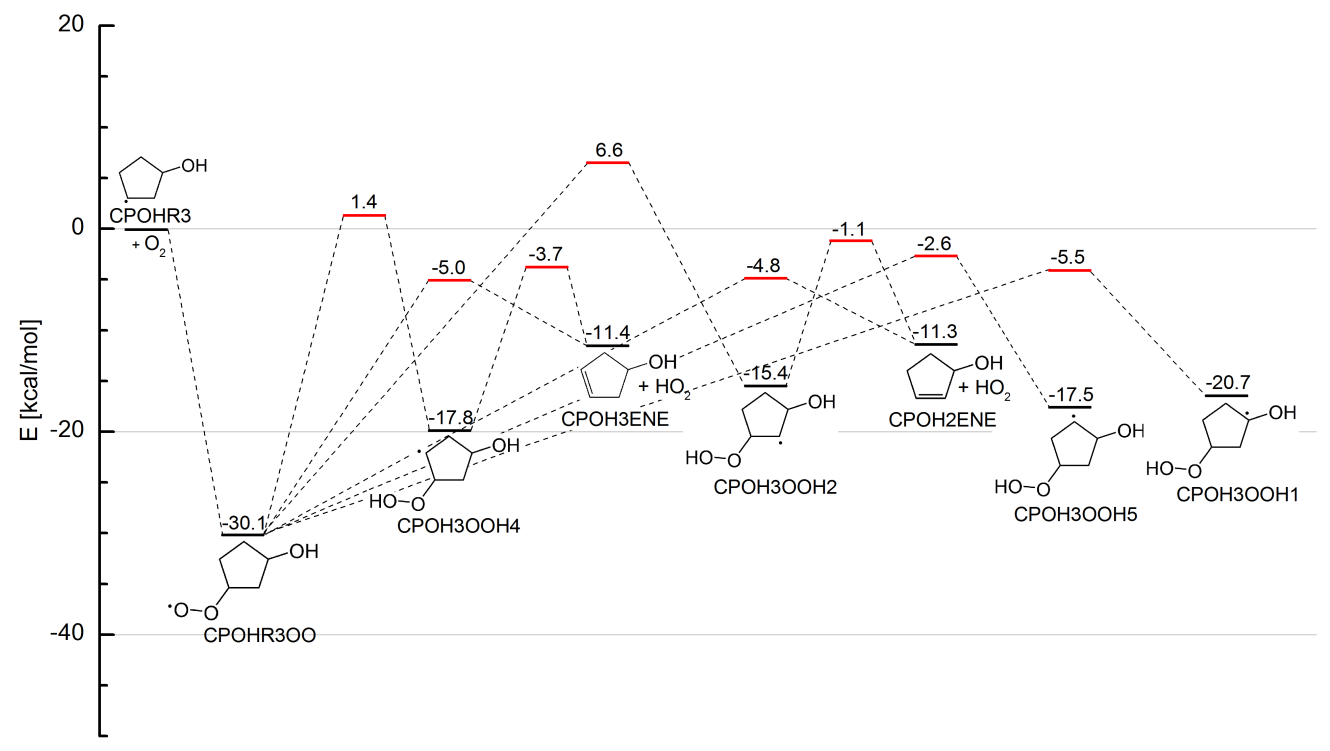

Figure 5: Potential energy surface for 3-hydroxycyclopentyl radical $+\mathrm{O}_{2}$. 


\subsection{Energy barrier for ring-opening reactions of fuel radicals}

In addition to the exploration of the low temperature chemistry of fuel radicals, their high temperature kinetics is investigated with regards to the barrier heights of ring-opening reactions. The $\beta$-scission of fuel radicals is a very important reaction step in hydrocarbon oxidation. For saturated compounds with carbocyclic structures, the rings can open via $\beta$-scission of a $\mathrm{C}-\mathrm{C}$ bond and species with a double bond are formed. In general, the energy barriers of ring-opening reactions are approximately identical to those of the $\beta$-scission reactions of linear alkyl radicals. Wang et al. [30] reported an enthalpy barrier of $33.5 \mathrm{kcal} / \mathrm{mol}$ for the ring opening of the cyclopentyl radical via $\mathrm{C}-\mathrm{C} \beta$-scission. This value is similar to those reported for alkyl radicals including pentyl radicals $[31,32]$. However, recent studies $[1,33]$ revealed that the ring-opening reactions of tetrahydrofuranyl species need relatively low energy barriers of $\sim 24 \mathrm{kcal} / \mathrm{mol}$, if they take place via $\mathrm{C}-\mathrm{O}$ bond $\beta$-scissions forming consequently ketones or aldehydes. The low energy barriers favor these reactions, especially at low temperatures, leading to the inhibition of the oxidation of fuel radicals.

In this work, the energy barriers of ring-opening reactions are estimated in the same way as in [1] for comparison. The calculation is performed at the CBS-QB3 level with an ultrafine grid and the keywords calcall, noeigentest, and verytight for transition state optimization. Zero-point energy correction is taken into account. The results are shown in Fig. 6. The five ringopening channels have energy barriers ranging from 31 to $36 \mathrm{kcal} / \mathrm{mol}$. The formation of the 2-hydroxy-4-penten-1-yl radical (C5H8OH2D-A) from the 3-hydroxycyclopentyl radical has the lowest energy barrier, while the highest- 
energy is estimated for the reaction with the same reactant but forming the 1-hydroxy-4-penten-1-yl radical (C5H8OH1-4). These values are on a similar level as that for the cyclopentyl radical [30] and are much higher than those for tetrahydrofuranyl molecules [1,33]. The ring-opening reactions of hydroxycyclopentyl radicals are expected to take place only at intermediate and high temperatures.
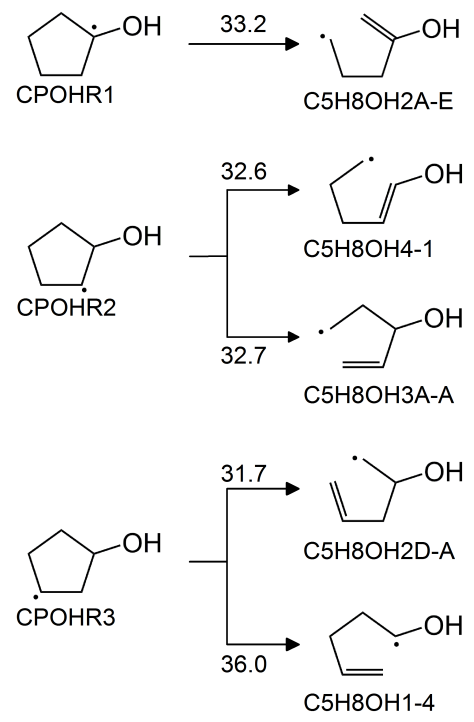

Figure 6: Energy barriers for ring-opening reactions of hydroxycyclopentyl radicals $[\mathrm{kcal} / \mathrm{mol}]$.

\section{Chemical kinetic modeling}

Following the results presented in Section 2, a chemical mechanism has been developed for cyclopentanol. The proposed mechanism includes both low and high temperature oxidation kinetics. The extensively validated $\mathrm{C}_{0^{-}}$ $\mathrm{C}_{4}$ mechanism from Blanquart et al. [34] serves as the base mechanism. 
This mechanism also contains the detailed chemistry of substituted aromatic species with emphasis on soot precursors [35], allowing the prediction of Polycyclic Aromatic Hydrocarbon (PAH) formation in the cyclopentanol oxidation. Recently, Al Rashidi et al. [29] developed a detailed reaction scheme for cyclopentane based on the approach of reaction classes, which has been applied successfully to derive chemical mechanisms of hydrocarbon species [27, 29, 36] including alcohols [17-19] and cyclic molecules [1, 37]. The present cyclopentanol-specific chemistry is thus derived based on the same concept and following the hierarchical nature of the cyclopentane mechanism. The 30 reaction classes proposed by Sarathy et al. [27] are taken into account in the model development. Reaction classes specific for alcohol oxidation, such as the direct aldehyde formation from the $\alpha$-fuel radical, are included in the mechanism. A table (Table S1) summarizing the considered reaction classes can be found in the Supplementary Material. The rate constants of reactions are assigned according to analogous reactions of structurally similar molecules, such as cyclopentane [29], if accurate calculated rate constants are available for analogous reactions. Modification of rate constants is made according to the results of BDEs and PESs, if necessary. For the case that calculated rate constants are lacking for reactions of similar molecules, the rate constants are specified according to the rate rules proposed in the literature. The entire mechanism consists of 278 species along with 2714 reactions (forward and backward counted separately) and is available as Supplementary Material. The reactions are written reversibly. Details about the model features are provided in the following. 


\subsection{H-abstraction reactions of cyclopentanol}

Hydrocarbon fuels are consumed primarily by $\mathrm{H}$-atom abstraction reactions during their oxidation. Thus, these reactions are in general very sensitive for the prediction of combustion targets, such as ignition delay times, as identified in the sensitivity analyses presented in Part II. Due to the missing literature studies on these reactions of cyclopentanol, their rate constants are estimated in this study based on the analogous reactions of cyclopentane. As the $\mathrm{OH}$ moiety affects the strength of $\mathrm{C}-\mathrm{H}$ bonds, leading to different $\mathrm{C}$ $\mathrm{H}$ BDEs compared to that of cyclopentane, the reaction rate constants are modified accordingly.

The activation energies $\left(E_{a}\right)$ of reactions were modified following the Evans-Polanyi correlation [38], which states the linear relationship of the reaction enthalpy or energy with the activation energy. Following the work of Sarathy et al. [17], the modification of activation energy follows the equation,

$$
E_{a, \text { cyclopentanol }}=E_{a, \text { cyclopentane }}+f\left(\mathrm{BDE}_{\text {cyclopentanol }}-\mathrm{BDE}_{\text {cyclopentane }}\right)
$$

Here, $f$ is a factor depending on the abstracting species and is normally between 0-1. Dean and Bozzelli [39] estimated factors of 0.65, 0.75, 0.50, 0.65 , and 0.60 for the species of $\mathrm{H}, \mathrm{O}, \mathrm{OH}, \mathrm{CH}_{3}$, and $\mathrm{HO}_{2}$, respectively, which have been often considered in model development, especially for alcohols [15, 40], and which were also used in this work. For other abstracting species, a factor of unity was employed in absence of information. In addition, the preexponential factors $(A)$ were corrected for degeneracy, as the rate coefficients of $\mathrm{H}$-abstraction reactions are on per-H-atom-basis. 
As mentioned in Section 2.3, the inhibition of the isomerization via bicyclic transition states favors the concerted $\mathrm{HO}_{2}$ elimination of peroxy radicals in the oxidation of cyclic compounds [28, 29]. For example, Al Rashidi et al. [29] highlighted the dominance of the formation of cyclopentene and $\mathrm{HO}_{2}$ directly from cyclopentyl peroxy radicals or via the formally direct pathway of cyclopentyl radical $+\mathrm{O}_{2}$ in the oxidation of cyclopentane. Analogous reactions are found in the present study to be of major importance in the oxidation of cyclopentanol as well. Due to the large number of $\mathrm{HO}_{2}$ radicals produced from these reactions, the $\mathrm{H}$-atom abstraction reactions by $\mathrm{HO}_{2}$ radical are important over the entire temperature range, which is confirmed by the results of the sensitivity analyses of ignition delay times on elementary reactions shown in Part II. For good model prediction of ignition delay times, the $\mathrm{A}$ factors of the three $\mathrm{H}$-abstraction reactions by $\mathrm{HO}_{2}$ radicals were increased by a factor of 2.5 consistently, keeping the branching ratios between them unchanged. The impact of this modification on the prediction of ignition delay times is demonstrated in Fig. S1 available in the Supplementary material.

\subsection{Ring-opening reactions of hydroxycyclopentyl radicals}

MAt high temperatures, the ring-opening reactions via $\mathrm{C}-\mathrm{C} \beta$-scission are supposed to be important consumption pathways for fuel radicals. Their energy barriers are estimated to be $31-36 \mathrm{kcal} / \mathrm{mol}$, similar to the barrier height of the analogous reaction for cyclopentane [30]. Therefore, in the present mechanism, the rate constants for these reactions are determined based on analogy with cyclopentane. The reaction rate coefficient of the ring-opening of the cyclopentyl radical was investigated experimentally and 
numerically in the literature $[29,30,41,42]$. The results of these studies differ however by up to a factor of 16 [29]. Recently, Al Rashidi et al. [29] calculated the high-pressure limit rate constants of this reaction together with the $\mathrm{C}-\mathrm{H} \beta$-scission of cyclopentyl radicals at a high level of theory and determined subsequently the pressure-dependent rate constants based on the fall-off parameters from [30]. While Manion and Awan [43] reported that the $\mathrm{C}-\mathrm{C} / \mathrm{C}-\mathrm{H}$ branching ratio of cyclopentyl radicals predicted by these rate constants [29] is still different from their experimental observation, these most recently calculated pressure-dependent rate coefficients are taken in the mechanism for the $\mathrm{C}-\mathrm{C}$ and $\mathrm{C}-\mathrm{H} \beta$-scission reactions of hydroxycyclopentyl radicals.

\subsection{Reactions of cyclopentenol and cyclopentadienol}

Cyclopentenols are the products of the $\mathrm{C}-\mathrm{H} \beta$-scission of hydroxycyclopentyl radicals. In addition, it can be formed via both sequential and formally direct reactions of hydroxycyclopentyl radical $+\mathrm{O}_{2} \rightleftharpoons$ cyclopentenol $+\mathrm{HO}_{2}$. Following the work of Al Rashidi et al. [29] for cyclopentane, the five reaction classes listed below were incorporated into the mechanism to describe the oxidation of cyclopentenols.

- H-abstraction from cyclopentenol,

- decomposition of cyclopentenol,

- $\mathrm{O}$ and $\mathrm{OH}$ addition to cyclopentenol,

- decomposition of hydroxycyclopentenyl radicals,

- reaction of hydroxycyclopentenyl radicals with $\mathrm{HO}_{2}$ and $\mathrm{CH}_{3} \mathrm{O}_{2}$. 
The rate constants of these classes were assigned according either to the rate rules proposed by Sarathy et al. [27] or to the analogous reactions of cyclopentene [29] and methylcyclohexene [44].

In addition to the reaction classes mentioned above, one additional class is included in the reaction scheme, that is the formation of cyclopentadienol via the $\mathrm{C}-\mathrm{H} \beta$-scission of hydroxycyclopentenyl radicals. The rate coefficients of the derived reactions were determined based on the analogy with C-

$\mathrm{H} \beta$-scission of methylcyclohexenyl radicals [44]. The oxidation chemistry of cyclopentadienol was extracted from the JetSurF mechanism [45], which consists of the decomposition and $\mathrm{H}$-abstraction reactions of cyclopentadienol. For the major products of these reactions, cyclopentadiene and cyclopentadienoxy radical, detailed reaction pathways are already available in the mechanism from Blanquart et al. [34]. The reaction sequence of cyclopentenol $\rightleftharpoons$ hydroxycyclopentenyl radical $\rightleftharpoons$ cyclopentadienol is retained in the present mechanism with the aim to assess the potential formation of aromatic species directly from fuel-specific large intermediates.

\subsection{Low temperature chemistry of cyclopentanol}

The low temperature chemistry of hydrocarbon molecules is composed of two kinds of reactions, the dominant chain-branching pathways and the side chain reactions. The chain-branching pathway follows the reaction sequence of $\mathrm{R}+\mathrm{O}_{2} \rightleftharpoons \mathrm{RO}_{2} \rightleftharpoons \mathrm{QOOH}\left(+\mathrm{O}_{2}\right) \rightleftharpoons \mathrm{O}_{2} \mathrm{QOOH} \rightarrow 2 \mathrm{OH}+$ stable species. The side chain reactions include mainly the concerted elimination of $\mathrm{RO}_{2}$, cyclic ether formation, and $\beta$-scission of $\mathrm{QOOH}$. All these reactions are considered in the present mechanism.

Al Rashidi et al. [29] computed the PES of cyclopentyl $+\mathrm{O}_{2}$ reactions 
including $\mathrm{O}_{2}$ addition to $\mathrm{R}, \mathrm{RO}_{2}$ isomerization, $\mathrm{HO}_{2}$ elimination of $\mathrm{RO}_{2}$, cyclic ether formation, and $\beta$-scission of $\mathrm{QOOH}$ radicals. Their pressuredependent rate coefficients were calculated by using the UCCSD(T)-F12a/ccpVTZ-F12//M06-2X/6-311++G(d,p) level of theory and master equation analysis. These rate constants [29] were assigned for the analogous reactions of cyclopentanol. For the reactions involving H-atom abstraction, such as the $\mathrm{RO}_{2}$ isomerization, their rate constants were modified for degeneracy and the activation energies were modified with respect to the C-H BDEs by assuming the Evans-Polanyi correlation [38], as described in Section 3.1. Note that for the direct $\mathrm{HO}_{2}$ elimination from hydroxycyclopentyl peroxy radicals, the rate constants were modified only for degeneracy and the activation energies were exempted from correction. The theoretical study of Villano et al. [22] revealed that the rate constants of direct elimination reactions are independent of the nature of the broken $\mathrm{C}-\mathrm{H}$ and $\mathrm{C}-\mathrm{OO}$ bonds. For the reactions of the oxygen addition to $\mathrm{QOOH}$ radicals and the isomerization of $\mathrm{O}_{2} \mathrm{QOOH}$ radicals, the rate constants of the first $\mathrm{O}_{2}$ addition and the isomerization of $\mathrm{RO}_{2}$ were used. This simplification was suggested by Villano et al. [46] and has been adopted in the literature works on mechanism development [29, 47], in the absence of accurate rate determination for the aforementioned reactions. The rate coefficients of the decomposition of ketohydroperoxides were specified using the rate constants calculated by Jalan et al. [48] for analogous reactions of $\mathrm{C}_{3}$-ketohydroperoxides.

The conventional $\mathrm{O}_{2} \mathrm{QOOH}$ isomerization takes place via the intramolecular migration of a hydrogen atom from the carbon site bounded with the $\mathrm{OOH}$ group. This is infeasible for the 1-hydroperoxy-1-hydroxycyclopentyl 
peroxy radical, as there is no $\mathrm{H}$-atom available at the $\alpha$-carbon site. To complete its consumption, alternative isomerization pathways [47] are included for the 1-hydroperoxy-1-hydroxycyclopentyl peroxy radical in the present mechanism, which proceed via intramolecular H-transfer from a normal carbon site to form di-hydroperoxy radical $\mathrm{P}(\mathrm{OOH})_{2}$. For the sake of model simplification, only the channels with six-membered transition states were taken into account due to their lower energy barriers, following the literature studies $[47,49]$. The formed $\mathrm{P}(\mathrm{OOH})_{2}$ radical can either decompose to a cyclic ether and an $\mathrm{OH}$ radical or go through a $\beta$-scission yielding an olefin and a hydroperoxy radical. The rate constants of these reactions were specified using the rate rules proposed by Bugler et al. [47]. It should be noted that the prediction of combustion properties of cyclopentanol, such as ignition delay times, is barely affected by these alternative pathways. The 1-hydroperoxy-1-hydroxycyclopentyl peroxy radical is formed via the reaction chain initialized by the oxidation of the 1-hydroxycyclopentyl radical. Its concentration is very low, as the 1-hydroxycyclopentyl radical mainly reacts with oxygen to form cyclopentanone and $\mathrm{HO}_{2}$, as discussed previously in Section 2.3 and later in Section 5.

\subsection{Formally direct reactions}

Al Rashidi et al. [29] added the formally direct reactions [50] on the PES of cyclopentyl $+\mathrm{O}_{2}$ into their mechanism of cyclopentane. It was found that several formally direct reactions show remarkable contribution to the consumption of cyclopentane [51]. Especially, the reaction of cyclopentyl + $\mathrm{O}_{2}$ going directly to cyclopentene $+\mathrm{HO}_{2}$ is faster than the stabilization of the cyclopentyl $+\mathrm{O}_{2}$ adduct and is very important over the entire temper- 
ature range at pressures larger than 1 bar. These well-skipping channels are thus also included in the present scheme. To retain a compact model size, only the following formally direct reactions are included in addition to their sequential reactions due to their major importance revealed in the oxidation of cyclopentane [51]:

- $\mathrm{R}+\mathrm{O}_{2} \rightleftharpoons$ Cyclopentenol $+\mathrm{HO}_{2}$,

- $\mathrm{R}+\mathrm{O}_{2} \rightleftharpoons \mathrm{QOOH}$.

Their rate constants were specified using analogous rate constants of cyclopentane. Other formally direct pathways, such as those between $\beta$-scission products of $\mathrm{QOOH}$ and $\mathrm{R}+\mathrm{O}_{2}, \mathrm{RO}_{2}$, cyclic ether $+\mathrm{OH}$, or cyclopentenol $+\mathrm{HO}_{2}$ were not considered. Their analogous reactions were found to have much smaller reaction constants than the sequential reactions and play a marginal role in the oxidation of cyclopentane [51].

\subsection{Alcohol-specific pathways}

The oxidation chemistry of linear alcohols has been investigated extensively in the literature $[17,18,52,53]$. Both theoretical and modeling studies $[17,21,54]$ confirmed that the major alcohol-specific reaction is the formation of aldehyde and $\mathrm{HO}_{2}$ from the $\mathrm{O}_{2}$ addition to $\alpha$-hydroxyalkyl radical. This is also found in the theoretical investigation of this study (Section 2.3). In the oxidation of cyclopentanol, the $\alpha$-radical, i. e., the 1-hydroxycyclopentyl radical, reacts with $\mathrm{O}_{2}$ yielding cyclopentanone and $\mathrm{HO}_{2}$ with a very low energy barrier. For this important reaction, the rate coefficient was assigned according to the pressure-dependent rate constant of 
$\alpha$-hydroxyethyl radical $+\mathrm{O}_{2} \rightleftharpoons$ acetaldehyde $+\mathrm{HO}_{2}$, which was calculated by da Silva et al. [54].

Following the work of Sarathy et al. [2], Waddington type reactions were taken into account. $\beta-\mathrm{RO}_{2}$ radical can isomerize via a six-membered ring to abstract an $\mathrm{H}$ atom from the hydroxyl moiety and decompose subsequently. Welz et al. $[52,53]$ discovered a set of unconventional reactions in the oxidation of alcohols. Hydrogen shift from the $\mathrm{OH}$ group was found to be important in the oxidation of iso-pentanol for the $\gamma$ - and $\delta$-hydroxyalkyl peroxy radicals via 7 - and 8-membered transition state rings. In addition, an $\mathrm{H}_{2} \mathrm{O}$ elimination reaction from hydroxyalkyl hydroperoxide radicals was detected, where the hydroperoxide is on the $\gamma$-site and the radical is on the $\alpha$-site. These reactions are considered in the present model. As the $\delta$ peroxy radical does not exist in the oxidation of cyclopentanol, the H-atom migration from the $\mathrm{OH}$ group is only included for the $\gamma$-peroxy radical. The rate constants of these reactions were specified based on the recent study of Sarathy et al. [15] for iso-pentanol and their activation energies were increased by $4 \mathrm{kcal} / \mathrm{mol}$ to account for the high energy barriers required by the bicyclic transition states.

\subsection{Cyclopentanone chemistry}

Cyclopentanone is the direct product from the alcohol-specific reaction of 1-hydroxycyclopentyl $+\mathrm{O}_{2}$. Its combustion chemistry has been investigated in the literature in terms of fundamental kinetics $[55,56]$, thermodynamic properties [57], and combustion characteristics [58, 59]. Very recently, Thion et al. [59] studied the oxidation of cyclopentanone in a jet-stirred reactor and proposed a chemical mechanism to describe its oxidation behavior. In the 
present study, the cyclopentanone mechanism from Thion et al. [59] has been incorporated into the cyclopentanol mechanism to describe the reaction of cyclopentanone. Further validation of this cyclopentanone mechanism [59] can improve the reliability of the cyclopentanol mechanism.

\subsection{Thermodynamic and transport properties}

As described in Section 2.1, the thermochemical data of a set of major species were calculated using quantum chemistry methods. For the remaining species, their data were calculated using the THERM code [60], in which the specific heat, heat of formation, and standard entropy of molecules were estimated based on the group additivity rules [61]. Revised group values proposed by Burke et al. [62] were considered in the calculation. The transport properties were estimated using the RMG code [63].

\section{Model validation}

The developed mechanism is validated against the measured ignition delay times, laminar burning velocities, and extinction strain rates of cyclopentanol. As part of this study, the ignition delay times were measured in a shock tube and a rapid compression machine at pressures of 20 and 40 bar over the temperature range of $690-1175 \mathrm{~K}$ for equivalence ratios of $0.5,1.0$, and 2.0. The laminar burning velocities of cyclopentanol/air mixtures were determined in a spherical combustion vessel for equivalence ratios of $0.8-1.3$ at pressures of 1.0 atm, 2.5, and 5.0 bar and initial temperatures of 398 and $433 \mathrm{~K}$. Extinction strain rates of non-premixed flames with cyclopentanol $/ \mathrm{N}_{2}$ $(463 \mathrm{~K})$ flowing against $\mathrm{O}_{2} / \mathrm{N}_{2}(300 \mathrm{~K})$ streams were measured in an atmospheric counterflow burner for fuel and oxygen mass fractions of $0.200-0.325$ 
and $0.223-0.310$, respectively. These extensive data sets not only serve as validation targets for the proposed mechanism, but also provide an assessment of the performance of cyclopentanol under different combustion modes. For detailed information about experimental configurations, measurement techniques, conditions, and model validation, the reader is referred to the Part II of this work.

As examples, the measured ignition delay times of lean, stoichiometric, and rich cyclopentanol $/ \mathrm{O}_{2} / \mathrm{N}_{2} / \mathrm{Ar}$ mixtures at a pressure of $40 \mathrm{bar}$ and the laminar burning velocities of cyclopentanol/air mixtures at pressures of 1.0 atm, 2.5, and 5.0 bar and at a temperature of $473 \mathrm{~K}$ are compared to those calculated using the developed mechanism in Figs. 7 and 8, respectively. The proposed model gives satisfactory results for these conditions. A comprehensive model validation is presented in Part II of this paper, along with the details about the computation and the comparison of cyclopentanol with structurally similar molecules, such as cyclopentane and $n$-pentanol.

\section{Oxidation pathway analysis}

For a detailed insight into the oxidation of cyclopentanol, an analysis of its reaction pathways was performed. The computation was carried out for the auto-ignition of stoichiometric cyclopentanol/air mixtures at a pressure of 20 bar and initial temperatures of 714 and $1111 \mathrm{~K}$, which are representative for low and high temperatures, respectively. The results are shown in Fig. 9. The reaction fluxes are given at $30 \%$ fuel consumption.

The oxidation of cyclopentanol is initialized by H-atom abstraction through reaction with molecular oxygen. This is not illustrated in Fig. 9 because of 


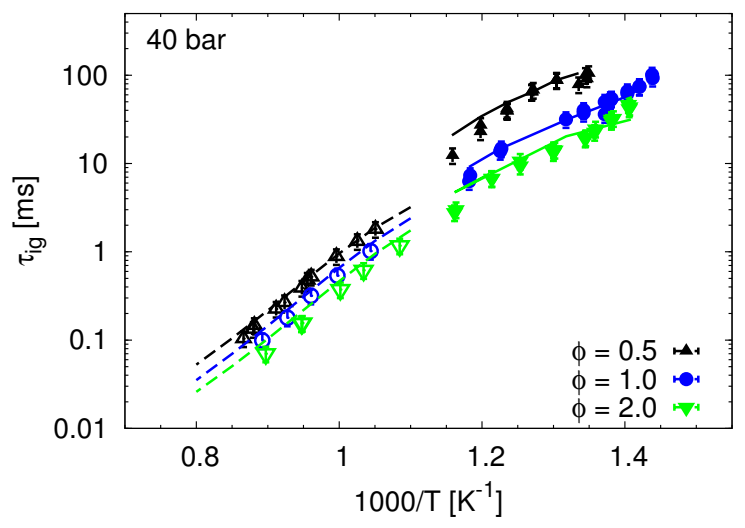

Figure 7: Ignition delay times of cyclopentanol $/ \mathrm{O}_{2} / \mathrm{N}_{2} / \mathrm{Ar}$ mixtures $\left(X_{\mathrm{O}_{2}} /\left(X_{\mathrm{N} 2}+\right.\right.$ $\left.\left.X_{\mathrm{AR}}\right)=21 / 79\right)$ at 40 bar. Solid and open symbols denote the data from rapid compression machine (RCM) and shock tube (ST), respectively. Solid and dashed lines show the computed results for RCM and ST, respectively. Facility effects of ST and RCM measurements were taken into account.

its relatively small contribution to the overall fuel consumption. As shown in Fig. 9, cyclopentanol is mainly consumed by the build up of $\mathrm{OH}$ and $\mathrm{HO}_{2}$ radicals at both low and high temperatures. At $714 \mathrm{~K}$, the $\mathrm{H}$-atom abstraction reactions by $\mathrm{OH}$ radicals are the major channels with a total contribution of $58 \%$. Due to the large amount of $\mathrm{HO}_{2}$ radicals being formed in the oxidation of cyclopentanol (discussed later), the $\mathrm{H}$-abstraction by $\mathrm{HO}_{2}$ radical is also very important at the relevant condition and consumes $41 \%$ of cyclopentanol. At the higher temperature of $1111 \mathrm{~K}$, the total contribution of the hydrogen abstraction reactions by $\mathrm{OH}$ and $\mathrm{HO}_{2}$ radicals is decreased to $51 \%$ and $37 \%$, respectively, as the abstraction reactions by $\mathrm{H}$ radicals become important (not depicted in Fig. 9). Through the abstraction of a hydrogen atom from cyclopentanol, three primary fuel radicals, CPOHR1, CPOHR2, 


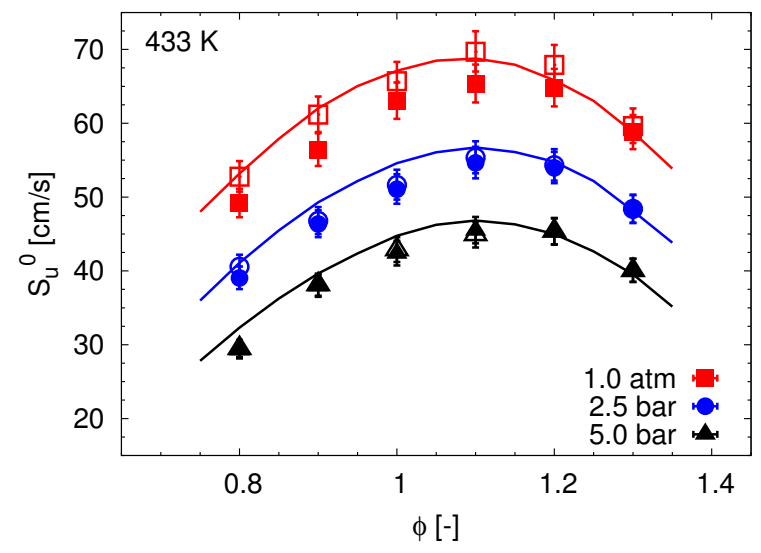

Figure 8: Laminar burning velocities of cyclopentanol/air mixtures at $1.0 \mathrm{~atm}, 2.5$, and 5.0 bar and $433 \mathrm{~K}$. Solid and open symbols are data from spherical combustion vessel experiments evaluated using non-linear and linear models, respectively. Lines show calculated results.

and CPOHR3, are formed. It can be seen in Fig. 9 that they are produced with similar amounts. Due to the low $\mathrm{C}-\mathrm{H} \mathrm{BDE}$ at the $\alpha$-carbon site and the decreased activation energy of the $\mathrm{H}$-abstraction reactions, the production of CPOHR1 would be expected to be very favorable at low temperatures. However, while the $\mathrm{C}-\mathrm{H}$ BDEs at the $\beta$ - and $\gamma$-carbon sites are higher than that of the $\alpha$-carbon, these unfavorable activation energies of reactions are compensated by their large pre-exponential factors, as four hydrogen atoms can be abstracted.

Consistent with the results shown on the PES diagram of CPOHR1 + $\mathrm{O}_{2}$ (Fig. 3) and those presented in the literature studies [17, 20, 21], the major consumption channel of the $\alpha$-alcohol fuel radical is the reaction with molecular oxygen to form stable cyclopentanone and $\mathrm{HO}_{2}$ radical. This chainpropagating reaction channel is able to retard the fuel ignition propensity at 


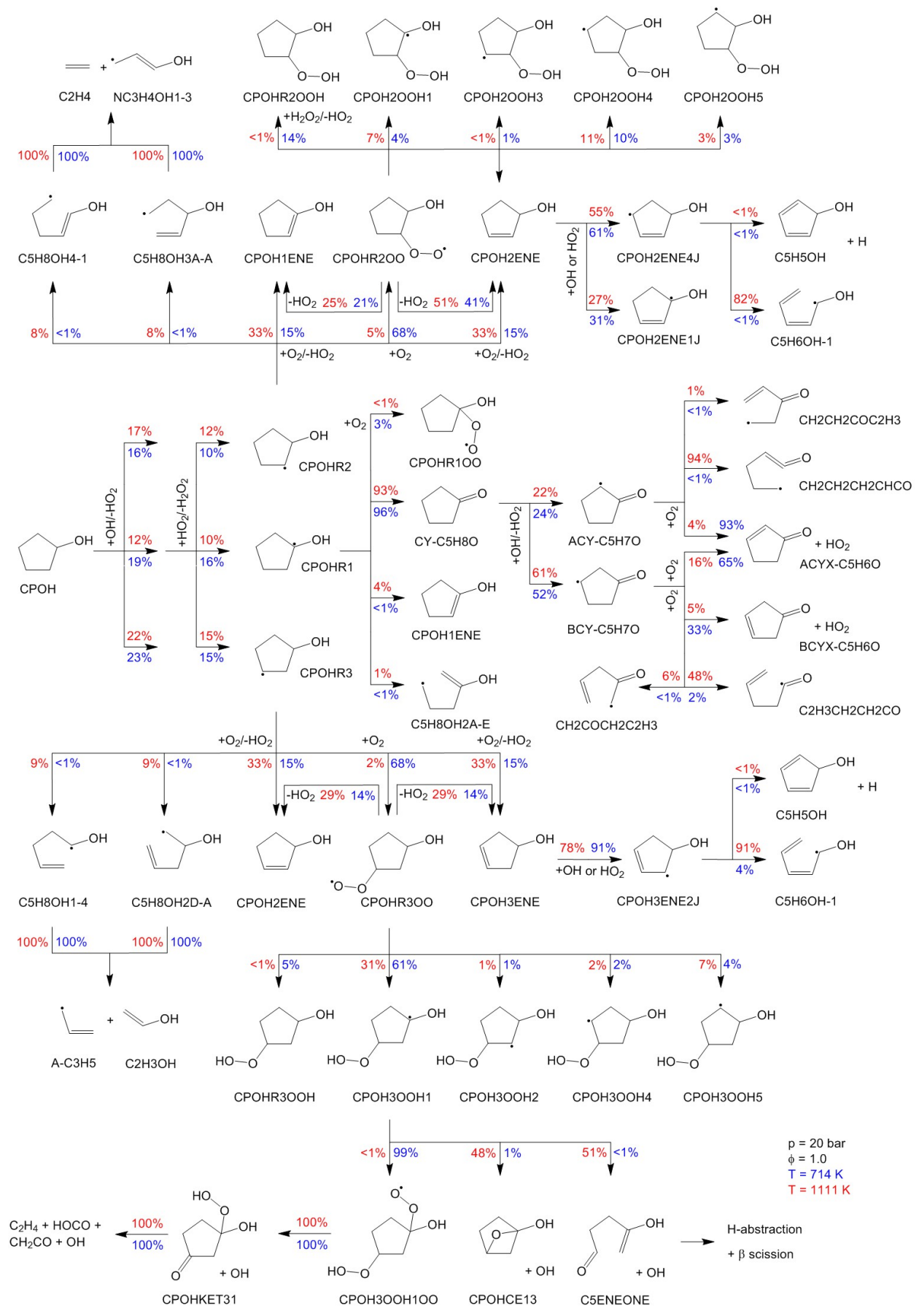

Figure 9: Reaction pathways during the auto-ignition of cyclopentanol/air mixtures at 20 bar, $714 \mathrm{~K}$ and $1111 \mathrm{~K}, \phi=1.0$, and $30 \%$ fuel consumption. 
low temperatures very strongly, as it suppresses the chain-branching pathways of the $\alpha$-radical almost completely [17-19]. Here, stable cyclopentanone is produced. As shown in Fig. 9, it releases afterwards an $\mathrm{H}$ atom by $\mathrm{OH}$ radical to give the cyclopentanoyl radicals, $\mathrm{ACY}-\mathrm{C} 5 \mathrm{H} 7 \mathrm{O}$ or $\mathrm{BCY}-\mathrm{C} 5 \mathrm{H} 7 \mathrm{O}$. At low temperatures, these two radicals react with molecular oxygen yielding cyclopentenones and $\mathrm{HO}_{2}$, while at high temperatures, they open the ring via the $\beta$-scission of the $\mathrm{C}$-C bond to form linear carbonyl radicals, which decompose directly to small intermediates. The low temperature product cyclopentenone undergoes H-abstraction and subsequent $\beta$-scission to produce final products. It should be noted that these reactions are part of the cyclopentanone mechanism from Thion et al. [59]. The reader is referred to the work of Thion et al. [59] for detailed insights into the cyclopentanone oxidation.

The main reaction pathways of the $\beta$-fuel radical are illustrated in the upper part of Fig. 9. In the low temperature range, the mechanism of CPOHR2 is governed mainly by the addition of molecular oxygen and the formation of the peroxy radical. It can be seen that the two formally direct pathways of CPOHR2 $+\mathrm{O}_{2} \rightleftharpoons$ cyclopentenols $+\mathrm{HO}_{2}$ are also crucial at the lower temperature of $714 \mathrm{~K}$, with a total contribution of $30 \%$ to the consumption of CPOHR2. The importance of these formally direct pathways even increases, when the oxidation occurs at higher temperatures. As presented, they consume $66 \%$ of CPOHR2 at $1111 \mathrm{~K}$, while the conventional $\beta$-scission reactions have a total contribution of $16 \%$. This agrees with the results of Al Rashidi et al. [51], who showed that the analogous reaction of cyclopentyl radicals $+\mathrm{O}_{2} \rightleftharpoons$ cyclopentene $+\mathrm{HO}_{2}$ is of large importance in the oxidation 
of cyclopentane at both low and high temperatures. $68 \%$ of CPOHR2 are oxidized to give CPOHR2OO at the low temperature of $714 \mathrm{~K}$, for which seven major reaction channels are illustrated in Fig 9, including four isomerization and two concerted elimination reactions. Among these channels, the $\mathrm{HO}_{2}$ elimination reactions are dominant. The low temperature chainbranching channel through the isomerization of $\mathrm{RO}_{2}$ is inhibited by the high energy barriers of bicyclic transition states. Overall, the important reaction pathways of the 2-hydroxycyclopentyl radical are very similar to those of cyclopentyl radicals shown in [51], which mainly involve the $\mathrm{O}_{2}$ addition to $\mathrm{R}$, the formally direct reactions of $\mathrm{R}+\mathrm{O}_{2} \rightleftharpoons$ alkene $+\mathrm{HO}_{2}$, and the concerted elimination of $\mathrm{RO}_{2}$.

Both of the sequential and formally direct reactions of $\mathrm{HO}_{2}$ elimination from $\mathrm{R}+\mathrm{O}_{2}$ produce cyclopentenols. The fate of the cyclopentenols is demonstrated in Fig. 9 using 2-cyclopentenol (CPOH2ENE) as an example. CPOH2ENE releases a hydrogen by reaction with $\mathrm{OH}$ and $\mathrm{HO}_{2}$ radicals, yielding hydroxycyclopentenyl radicals. These radicals open the ring via $\beta$ scission at high temperatures. At low temperatures, they react mainly with $\mathrm{HO}_{2}$ radicals to give a smaller alkyl radical, a stable carbonyl, and an $\mathrm{OH}$ radical (not shown in Fig. 9), as proposed by Sarathy et al. [27] for alkenyl radicals in the oxidation of alkanes. As described in Section 3, the formation pathways of cyclopentadienol $(\mathrm{C} 5 \mathrm{H} 5 \mathrm{OH})$ from hydroxycyclopentenyl radicals via $\mathrm{C}-\mathrm{H} \beta$-scission and its consumption channels are incorporated in the mechanism to evaluate the potential PAH formation from fuel-specific intermediates. Nevertheless, this pathway is found to be of marginal importance here, indicating a negligible contribution of large intermediates to PAH 
formation.

The reactions of the $\gamma$-fuel radical are similar to those of CPOHR2. Differences are revealed in the consecutive pathways of the formed peroxy radical CPOHR3OO. The concerted elimination of CPOHR3OO shows decreased contribution to its total consumption in comparison to that of CPOHR2OO. Furthermore, one of the isomerization channels of CPOHR3OO is dominant at the investigated condition. As already observed on the PES of 3hydroxycyclopentyl $+\mathrm{O}_{2}$ (Fig. 5), this isomerization reaction has a barrier height lower than the $\mathrm{HO}_{2}$ elimination reactions, because it involves a sixmembered transition state ring associated with a low energy barrier and in addition, its intramolecular $\mathrm{H}$ atom abstraction is favored by the very low $\mathrm{C}-\mathrm{H} \mathrm{BDE}$ at the tertiary $\alpha$-carbon site. This reaction promotes the chain-branching pathway of the $\gamma$-fuel radical. The isomerization product, $\mathrm{CPOH} 3 \mathrm{OOH} 1$, is oxidized by the second $\mathrm{O}_{2}$ addition to yield the $\mathrm{CPOH} 3 \mathrm{OOH} 1 \mathrm{OO}$ radical, which isomerizes and then decomposes to give an $\mathrm{OH}$ radical and a ketohydroperoxide (CPOHKET31). The CPOHKET31 decomposes further to form stable small species and releases the second $\mathrm{OH}$ radical, which completes the chain-branching path. At the higher temperature of $1111 \mathrm{~K}$, the CPOH3OOH1 either cyclizes to form ether (CPOHCE13) or dissociates to give a ketone (C5ENEONE). Both reactions produce only one $\mathrm{OH}$ radical, leading to chain-propagation. The CPOHCE13 and C5ENEONE are consumed via $\mathrm{H}$-atom abstraction and subsequent $\beta$-scission to form smaller species. The impact of these two chain-propagation channels on the fuel reactivity is, however, marginal at the temperature of $1111 \mathrm{~K}$, as only $2 \%$ of CPOHR3 are oxidized to peroxy radicals. 
Overall, it is found that the reaction pathways of the $\alpha$-fuel radical are strongly different from those of the $\beta$ - and $\gamma$-fuel radicals. At both low and high temperatures, the $\alpha$-hydroxycyclopentyl radical reacts preferably with $\mathrm{O}_{2}$, yielding stable cyclopentanone and $\mathrm{HO}_{2}$ radical. For $\beta$ - and $\gamma$-radicals, the formally direct reactions of $\mathrm{R}+\mathrm{O}_{2} \rightleftharpoons$ cyclopentenol $+\mathrm{HO}_{2}$ contribute to more than $60 \%$ of their consumption at high temperatures. In the low temperature range, they mainly combine with oxygen to form peroxy radicals. Differences are observed in the consecutive pathways of their peroxy radicals. While the $\beta$-peroxy radical eliminates $\mathrm{HO}_{2}$ to produce cyclopentenol, the chain-branching channel is more favored for the $\gamma$-peroxy radical due to the low energy barrier of an isomerization reaction that proceeds via a six-membered intramolecular hydrogen transfer from the $\alpha$-carbon site.

\section{Concluding remarks}

In this work, the oxidation chemistry of cyclopentanol has been studied numerically for the first time. Besides the thermochemistry, its oxidation kinetics is explored using ab initio methods in terms of the $\mathrm{C}-\mathrm{H}$ bond dissociation energies of cyclopentanol, the energy barriers of ring-opening reactions, and the potential energy surfaces of oxidation reactions of cyclopentanol radicals. Based on the theoretical evidence, a chemical mechanism is derived for the low to high temperature oxidation of cyclopentanol by following the hierarchical nature of a published cyclopentane mechanism [29] and simultaneously taking the nature of the alcohol group into account. The model was validated for auto-ignition, premixed flames, and counterflow diffusion flames of cyclopentanol in Part II and used here to elucidate the major ox- 
idation pathways of cyclopentanol. It is found that the alcohol functional group introduces two major features into the reaction pathways, compared to those of cyclopentane. First, it facilitates an alcohol-specific $\mathrm{HO}_{2}$ elimination reaction for the $\alpha$-hydroxycyclopentyl radical, which decreases the fuel reactivity at low temperatures strongly. Second, it reduces the $\mathrm{C}-\mathrm{H}$ BDE at the $\alpha$-carbon site and consequently the barrier height of the intramolecular H-migration from this site, thus promoting the chain-branching channel of the $\gamma$-peroxy radical in the low temperature range slightly.

\section{Acknowledgments}

This work is funded by the Deutsche Forschungsgemeinschaft (DFG, German Research Foundation) under Germany's Excellence Strategy - Exzellencluster 2186 "The Fuel Science Center" ID: 390919832. Dr. Narayanaswamy gratefully acknowledges the "Indo-German Center for Sustainability (IGCS)" via the "short-term academic exchange initiative" at the Indian Institute of Technology Madras for supporting her visit to RWTH Aachen University. The work at KAUST was supported by the Clean Fuels Consortium and its member companies.

\section{References}

[1] L. Cai, H. Minwegen, J. Beeckmann, U. Burke, R. Tripathi, A. Ramalingam, L.C. Kröger, A. Sudholt, K. Leonhard, J. Klankermayer, K.A. Heufer, H. Pitsch, Experimental and numerical study of a novel biofuel: 2-Butyltetrahydrofuran, Combustion and Flame 178 (2017) 257-267. 
[2] S.M. Sarathy, P. Oßwald, N. Hanson, K. Kohse-Höinghaus, Alcohol combustion chemistry, Progress in Energy and Combustion Science 44 (2014) 40-102.

[3] A. Voll, W. Marquardt, Reaction network flux analysis: Optimizationbased evaluation of reaction pathways for biorenewables processing, AIChE Journal 58 (2012) 1788-1801.

[4] M. Dahmen, W. Marquardt, Model-based formulation of biofuel blends by simultaneous product and pathway design, Energy \& Fuels 31 (2017) 4096-4121.

[5] X.-L. Li, J. Deng, J. Shi, T. Pan, C.-G. Yu, H.-J. Xu, Y. Fu, Selective conversion of furfural to cyclopentanone or cyclopentanol using different preparation methods of $\mathrm{Cu}-\mathrm{Co}$ catalysts, Green Chemistry 17 (2015) 1038-1046.

[6] Y. Wang, M. Zhou, T. Wang, G. Xiao, Conversion of furfural to cyclopentanol on $\mathrm{Cu} / \mathrm{Zn} / \mathrm{Al}$ catalysts derived from hydrotalcite-like materials, Catalysis Letters 145 (2015) 1557-1565.

[7] M.J. Frisch, G.W. Trucks, H.B. Schlegel, G.E. Scuseria, M.A. Robb, J.R. Cheeseman, G. Scalmani, V. Barone, B. Mennucci, G.A. Petersson, H. Nakatsuji, M. Caricato, X. Li, H.P. Hratchian, A.F. Izmaylov, J. Bloino, G. Zheng, J.L. Sonnenberg, M. Hada, M. Ehara, K. Toyota, R. Fukuda, J. Hasegawa, M. Ishida, T. Nakajima, Y. Honda, O. Kitao, H. Nakai, T. Vreven, J.A. Montgomery Jr., J.E. Peralta, F. Ogliaro, M. Bearpark, J.J. Heyd, E. Brothers, K.N. Kudin, V.N. Staroverov, 
R. Kobayashi, J. Normand, K. Raghavachari, A. Rendell, J.C. Burant, S.S. Iyengar, J. Tomasi, M. Cossi, N. Rega, J.M. Millam, M. Klene, J.E. Knox, J.B. Cross, V. Bakken, C. Adamo, J. Jaramillo, R. Gomperts, R.E. Stratmann, O. Yazyev, A.J. Austin, R. Cammi, C. Pomelli, J.W. Ochterski, R.L. Martin, K. Morokuma, V.G. Zakrzewski, G.A. Voth, P. Salvador, J.J. Dannenberg, S. Dapprich, A.D. Daniels, O. Farkas, J.B. Foresman, J.V. Ortiz, J. Cioslowski, D.J. Fox, Gaussian09 Revision D.01, http://www.gaussian.com/g_prod/g09.htm, gaussian Inc. Wallingford CT 2009.

[8] K.K. Irikura, R.D. Johnson, R.N. Kacker, Uncertainties in scaling factors for ab initio vibrational frequencies, The Journal of Physical Chemistry A 109 (2005) 8430-8437.

[9] J. Zheng, T. Yu, E. Papajak, I.M. Alecu, S.L. Mielke, D.G. Truhlar, Practical methods for including torsional anharmonicity in thermochemical calculations on complex molecules: The internal-coordinate multi-structural approximation, Physical Chemistry Chemical Physics 13 (2011) 10885-10907.

[10] J.E. Kilpatrick, K.S. Pitzer, R. Spitzer, The thermodynamics and molecular structure of cyclopentane, Journal of the American Chemical Society 31 (1947) 2483-2488.

[11] Y.-Y. Chuang, D.G. Truhlar, Statistical thermodynamics of bond torsional modes, The Journal of Chemical Physics 112 (2000) 1221-1228.

[12] B.J. McBride, S. Gordon, M.A. Reno, Coefficients for calculating ther- 
modynamic and transport properties of individual species, NASA Technical Memorandum 4513 (1993).

[13] G.J. Kabo, V.V. Diky, A.A. Kozyro, A.P. Krasulin, V.M. Sevruk, Thermodynamic properties, conformational, composition, phase transitions of cyclopentanol, The Journal of Chemical Thermodynamics 27 (1995) $953-967$.

[14] K.B. Wiberg, D.J. Wassermann, E.J. Martin, M.A. Murcko, Journal of the American Chemical Society 107 (1985) 6019-6022.

[15] S.M. Sarathy, S. Park, B.W. Weber, W. Wang, P.S. Veloo, A.C. Davis, C. Togbé, C.K. Westbrook, O. Park, G. Dayma, Z. Luo, M.A. Oehlschlaeger, F.N. Egolfopoulos, T. Lu, W.J. Pitz, C.-J. Sung, P. Dagaut, A comprehensive experimental and modeling study of iso-pentanol combustion, Combustion and Flame 160 (2013) 2712-2728.

[16] S. Park, O. Mannaa, F. Khaled, R. Bougacha, M.S. Mansour, A. Farooq, S.K. Chung, S.M. Sarathy, A comprehensive experimental and modeling study of 2-methylbutanol combustion, Combustion and Flame 162 (2015) 2166-2176.

[17] S.M. Sarathy, S. Vranckx, K. Yasunaga, M. Mehl, P. Oßwald, W.K. Metcalfe, C.K. Westbrook, W.J. Pitz, K. Kohse-Höinghaus, R.X. Fernandes, H.J. Curran, A comprehensive chemical kinetic combustion model for the four butanol isomers, Combustion and Flame 159 (2012) 2028-2055.

[18] K.A. Heufer, S.M. Sarathy, H.J. Curran, A.C. Davis, C.K. Westbrook, 
W.J. Pitz, Detailed kinetic modeling study of $n$-pentanol oxidation, Energy \& Fuels 26 (2012) 6678-6685.

[19] L. Cai, Y. Uygun, C. Togbé, H. Pitsch, H. Olivier, P. Dagaut, S.M. Sarathy, An experimental and modeling study of $n$-octanol combustion, Proceedings of the Combustion Institute 35 (2015) 419-427.

[20] G. da Silva, J.W. Bozzelli, L. Liang, J.T. Farrrell, Ethanol oxidation: Kinetics of the $\alpha$-hydroxyethyl radical $+\mathrm{O}_{2}$ reaction, The Journal of Physics Chemistry A 113 (2009) 8923-8933.

[21] J. Zádor, R.X. Fernandes, Y. Georgievskii, G. Meloni, C.A. Taatjes, J.A. Miller, The reaction of hydroxyethyl radicals with $\mathrm{O}_{2}$ : A theoretical analysis and experimental product study, Proceedings of the Combustion Institute 32 (2009) 271-277.

[22] S.M. Villano, L.K. Huynh, H.H. Carstensen, A.M. Dean, High-pressure rate rules for alkyl $+\mathrm{O}_{2}$ reactions. 1 . The dissociation, concerted elimination, and isomerization channels of the alkyl peroxy radical, The Journal of Physical Chemistry A 115 (2011) 13425-13442.

[23] S. Sharma, S. Raman, W.H. Green, Intramolecular hydrogen migration in alkylperoxy and hydroperoxyalkylperoxy radicals: Accurate treatment of hindered rotors, The Journal of Physical Chemistry A 114 (2010) $5689-5701$.

[24] A. Miyoshi, Systematic computational study on the unimolecular reactions of alkylperoxy $\left(\mathrm{RO}_{2}\right)$, hydroperoxyalkyl $(\mathrm{QOOH})$, and hydroper- 
oxyalkylperoxy $\left(\mathrm{O}_{2} \mathrm{QOOH}\right)$ radicals, The Journal of Physical Chemistry A 115 (2011) 3301-3325.

[25] J. Zádor, C. Taatjes, R.X. Fernandes, Kinetics of elementary reactions in low-temperature autoignition chemistry, Progress in Energy and Combustion Science 37 (2011) 371-421.

[26] H.J. Curran, P. Gaffuri, W.J. Pitz, C.K. Westbrook, A comprehensive modeling study of $n$-heptane oxidation, Combustion and Flame 114 (1998) 149-177.

[27] S.M. Sarathy, C.K. Westbrook, M. Mehl, W.J. Pitz, C. Togbé, P. Dagaut, H. Wang, M.A. Oehlschlaeger, U. Niemann, K. Seshadri, P.S. Veloo, C. Ji, F.N. Egolfopoulos, T. Lu, Comprehensive chemical kinetic modeling of the oxidation of 2-methylalkanes from $\mathrm{C}_{7}$ to $\mathrm{C}_{20}$, Combustion and Flame 158 (2011) 2338-2357.

[28] Y. Yang, A. L. Boehman, J.M. Simmie, Uniqueness in the low temperature oxidation of cycloalkanes, Combustion and Flame 157 (2010) $2357-2368$.

[29] M.J. Al Rashidi, M. Mehl, W.J. Pitz, S. Mohamed, S.M. Sarathy, Cyclopentane combustion chemistry. Part I: Mechanism development and computational kinetics, Combustion and Flame 183 (2017) 358-371.

[30] K. Wang, S.M. Villano, A.M. Dean, Reactions of allylic radicals that impact molecular weight growth kinetics, Physical Chemistry Chemical Physics 17 (2015) 6255-6273. 
[31] A. Ratkiewicz, Kinetics of the C-C bond beta scission reactions in alkyl radicals, Physical Chemistry Chemical Physics 13 (2011) 15037-15046.

[32] A. Ratkiewicz, T.N. Truong, Kinetics of the C-C bond beta scission reactions in alkyl radical reaction class, The Journal of Physical Chemistry A 116 (2012) 6643-6654.

[33] B. Rotavera, J.D. Savee, I.O. Antonov, R.L. Caravan, L. Sheps, D.L. Osborn, J. Zádor, C.A. Taatjes, Influence of oxygenation in cyclic hydrocarbons on chain-termination reactions from $\mathrm{R}+\mathrm{O}_{2}$ : tetrahydropyran and cyclohexane, Proceedings of the Combustion Institute 36 (2017) $597-606$.

[34] G. Blanquart, P. Pepiot-Desjardins, H. Pitsch, Chemical mechanism for high temperature combustion of engine relevant fuels with emphasis on soot precursors, Combustion and Flame 156 (2009) 588-607.

[35] K. Narayanaswamy, G. Blanquart, H. Pitsch, A consistent chemical mechanism for oxidation of substituted aromatic species, Combustion and Flame 157 (2010) 1879-1898.

[36] M. Mehl, W.J. Pitz, C.K. Westbrook, H.J. Curran, Kinetic modeling of gasoline surrogate components and mixtures under engine conditions, Proceedings of the Combustion Institute 33 (2011) 193-200.

[37] W. Weber, W.J. Pitz, M. Mehl, E.J. Silke, A.C. Davis, C.-J. Sung, Experiments and modeling of the autoignition of methylcyclohexane at high pressure, Combustion and Flame 161 (2014) 1972-1983. 
[38] M.G. Evans, M. Polanyi, Inertia and driving force of chemical reactions, Transactions of the Faraday Society 34 (1938) 11-24.

[39] A.M. Dean, J.W. Bozzelli, Combustion chemistry of nitrogen, Gas-phase combustion chemistry, W.C. Gardiner Jr. (ed.), Springer, New York, 2000.

[40] J.T. Moss, A.M. Berkowitz, M.A. Oehlschlaeger, J. Biet, V. Warth, P.A. Glaude, F. Battin-Leclerc, An experimental and kinetic modelling study of the oxidation of the four isomers of butanol, The Journal of Physical Chemistry A 112 (2008) 10843-10855.

[41] B. Sirjean, P.-A. Glaude, M.F. Ruiz-Lopez, R. Fournet, Detailed kinetic study of the ring opening of cycloalkanes by CBS-QB3 calculations, The Journal of Physical Chemistry A 110 (2006) 12693-12704.

[42] I.A. Awan, D.R. Burgess Jr., W. Tsang, J.A. Manion, Shock tube study of the decomposition of cyclopentyl radicals, Proceedings of the Combustion Institute 33 (2011) 341-349.

[43] J.A. Manion, I.A. Awan, A shock tube study of $\mathrm{H}$ atom addition to cyclopentene, International Journal of Chemical Kinetics 50 (2018) 225242 .

[44] K. Narayanaswamy, H. Pitsch, P. Pepiot, A chemical mechanism for low to high temperature oxidation of methylcyclohexane as a component of transportation fuel surrogates, Combustion and Flame 162 (2015) 11931213. 
[45] H. Wang, E. Dames, B. Sirjean, D.A. Sheen, R. Tango, A. Violi, J.Y.W. Lai, F.N. Egolfopoulos, D.F. Davidson, R.K. Hanson, C.T. Bowman, C.K. Law, W. Tsang, N.P. Cernansky, D.L. Miller, R.P. Lindstedt, A high-temperature chemical kinetic model of $n$-alkane (up to $n$-dodecane), cyclohexane, and methyl-, ethyl-, $n$-propyl and $n$ butyl-cyclohexane oxidation at high temperatures, JetSurF version 2.0, http://web.stanford.edu/group/haiwanglab/JetSurF/JetSurF2.0/index.html (September 2010).

[46] S.M. Villano, L.K. Huynh, H.H. Carstensen, A.M. Dean, High-pressure rate rules for alkyl $+\mathrm{O}_{2}$ reactions. 2. The isomerization, cyclic ether formation, and $\beta$-scission reactions of hydroperoxy alkyl radicals, The Journal of Physical Chemistry A 116 (2012) 5068-5089.

[47] J. Bugler, K.P. Somers, E.J. Silke, H.J. Curran, Revisiting the kinetics and thermodynamics of the low-temperature oxidation pathways of alkanes: A case study of the three pentane isomers, The Journal of Physical Chemistry A 119 (2015) 7510-7527.

[48] A. Jalan, I.M. Alecu, R. Meana-Paeda, J. Aguilera-Iparraguirre, K.R. Yang, S.S. Merchant, D.G. Truhlar, W.H. Green, New pathways for formation of acids and carbonyl products in low-temperature oxidation: The korcek decomposition of $\gamma$-ketohydroperoxides, Journal of the American Chemical Society 135 (2013) 1100-11114.

[49] L. Cai, H. Pitsch, S.Y. Mohamed, V. Raman, J. Bugler, H.J. Curran, S.M. Sarathy, Optimized reaction mechanism rate rules for ignition of normal alkanes, Combustion and Flame 173 (2016) 468-482. 
[50] R.X. Fernandes, J. Zádor, L. E. Jusinski, J.A. Miller, C.A. Taatjes, Formally direct pathways and low-temperature chain branching in hydrocarbon autoignition: the cyclohexyl $+\mathrm{O}_{2}$ reaction at high pressure, Physical Chemistry Chemical Physics 11 (2009) 1320-1327.

[51] M.J. Al Rashidi, J.C. Mármol, C. Banyon, M.B. Sajid, M. Mehl, W.J. Pitz, S. Mohamed, A. Alfazazi, T. Lu, H.J. Curran, A. Farooq, S.M. Sarathy, Cyclopentane combustion chemistry. Part II. Ignition delay measurements and mechanism validation, Combustion and Flame 184 (2017) 372-385.

[52] O. Welz, J. Zádor, J.D. Savee, M.Y. Ng, G. Meloni, R.X. Fernandes, L. Sheps, B.A. Simmons, T.S. Lee, D.L. Osborn, C.A. Taatjes, Lowtemperature combustion chemistry of biofuels: pathways in the initial low-temperature $(550 \mathrm{~K}-750 \mathrm{~K})$ oxidation chemistry of isopentanol, Physical Chemistry Chemical Physics 14 (2012) 3112-3127.

[53] O. Welz, S.J. Klippenstein, L.B. Harding, C.A. Taatjes, J. Zádor, Unconventional peroxy chemistry in alcohol oxidation: The water elimination pathway, The Journal of Physical Chemistry Letters 4 (2013) 350-354.

[54] G. da Silva, J.W. Bozzelli, Role of the $\alpha$-hydroxyethylperoxy radical in the reactions of acetaldehyde and vinyl alcohol with $\mathrm{HO}_{2}$, Chemical Physics Letters 483 (2009) 25-29.

[55] C.W. Zhou, J.M. Simmie, W.J. Pitz, H.J. Curran, Toward the development of a fundamentally based chemical model for cyclopentanone: 
High-pressure-limit rate constants for $\mathrm{H}$ atom abstraction and fuel radical decomposition, The Journal of Physics Chemistry A 120 (2016) 7037-7044.

[56] A.M. Scheer, O. Welz, S.S. Vasu, D.L. Osborn, C.A. Taatjes, Low temperature (550-700 K) oxidation pathway of cyclic ketones: Dominance of $\mathrm{HO}_{2}$-elimination channels yielding conjugated cyclic coproducts, Physical Chemistry Chemical Physics 17 (2015) 12124-12134.

[57] O.V. Shvaro, A.D. Peshchenko, A.I. Sachek, V.S. Markovnik, V.M. Al'khimovich, Thermodynamic properties of cyclopentanone and cyclohexanone, Journal of engineering physics 52 (1987) 591-595.

[58] X. Bao, Y. Jiang, H. Xu, C. Wang, T. Lattimore, L. Tang, Laminar flame characteristics of cyclopentanone at elevated temperatures, Applied Energy 195 (2017) 671-680.

[59] S. Thion, C. Togbé, G. Dayma, Z. Serinyel, P. Dagaut, Experimental and detailed kinetic modeling study of cyclopentanone oxidation in a jet-stirred reactor at 1 and 10 atm, Energy \& Fuel 31 (2017) 2144-2155.

[60] E.R. Ritter, J.W. Bozzelli, THERM: Thermodynamic property estimation for gas phase radicals and molecules, International Journal of Chemical Kinetics 23 (1991) 767-778.

[61] S.W. Benson, Thermochemical Kinetics, 2nd Ed., John Wiley \& Sons, 1976.

[62] S.M. Burke, J.M. Simmie, H.J. Curran, Critical evaluation of thermochemical properties of $\mathrm{C}_{1}-\mathrm{C}_{4}$ species: Updated group-contributions to 
estimate thermochemical properties, Journal of Physical and Chemical Reference Data 44 (2015) 013101.

[63] W.H. Green, J.W. Allen, R.W. Ashcraft, G.J. Beran, C.A. Class, C. Gao, C.F. Goldsmith, M.R. Harper, A. Jalan, G.R. Magoon, D.M. Matheu, S.S. Merchant, J.D. Mo, S. Petway, S. Raman, S. Sharma, J. Song, K.M. Van Geem, J. Wen, R.H. West, A. Wong, H. Wong, P.E. Yelvington, J. Yu, RMG reaction mechanism generator version 3.3, http://rmg.sourceforge.net/ (2013). 